\title{
Experiences of Student Support in the Distance Mode Bachelor of Nursing Science Degree at the University of Namibia
}

\author{
Carol Denise Du Plessis ${ }^{1}$, Lucy Alexander ${ }^{1,}$ Daniel Opotamutale Ashipala ${ }^{2} \&$ Esther Kamenye $^{3}$ \\ ${ }^{1}$ Faculty of Community and Health, University of the Western Cape, Cape Town, South Africa \\ ${ }^{2}$ Department of General Nursing Science, School of Nursing, University of Namibia (UNAM), Keetmanshoop, \\ Namibia \\ ${ }^{3}$ Clara Barton School of Nursing, Welwitchia University, Windhoek, Namibia \\ Correspondence: Carol Denise Du Plessis, Clara Barton School of Nursing, Welwitchia University, Windhoek, \\ Namibia. PO Box 98604, Pelican Square, 183 Industria Street, Lafrenz, Windhoek, Namibia
}

Received: September 8, 2016

Accepted: September 27, 2016

Online Published: October 7, 2016

doi:10.5430/ijhe.v5n4p103

URL: http://dx.doi.org/10.5430/ijhe.v5n4p103

\begin{abstract}
The aim of this study was to understand the way in which students experienced the support services offered by the University of Namibia's distance education unit - the Centre for External Studies. The study explored students' experiences and their perceptions of the administrative, social and academic support services provided by the University of Namibia.

The research design was qualitative and exploratory with the study using focus groups and interviews for the purposes of data collection. The sample comprised forty Bachelor of Nursing Science students who were enrolled at both campuses of the university between 2005 and 2011, as well as seven staff members who were involved in the student support services. Relevant documents and interviews pertaining to the envisioned support services from the Centre for External Studies served as the basis for the evaluation of the services offered. The data were analysed using thematic content analysis. The findings from the two campuses were then compared.

The findings reflected positive experiences of support from both family and lecturers, as well as positive perceptions of institutional offerings such as video conferences. However, the study also found some institutional weaknesses in terms of programme delivery such as the late delivery of study materials, which had an impact on the students' submission of assignments, and inadequate communication systems which affected the delivery of support workshops.
\end{abstract}

Keywords: Distance education, Distance education support, Student support, Institutional barriers, Discontinued studies

\section{Introduction}

In 1996, the Ministry of Health and Social Services (MOHSS) in Namibia developed a long-term health human resource (HR) strategic framework which forecasted the future needs and supply of staff members who would be required in the country for the next thirty years (1997 to 2027). In The Health and Social Review of 2008, the MoHSS (2008) focused attention on the inadequate numbers of graduates leaving both the Ministry of Health Training Centres in Windhoek and Keetmanshoop and the University of Namibia (UNAM) with this resulting in an insufficient number of health professionals and sub-professionals to meet the country's needs. In 2007, the vacancy rate for the overall public sector stood at $27 \%$ while, in the same year, the institutional records of the MOHSS (2008) revealed an attrition rate for registered and enrolled nurses of $4 \%$.

In an effort to address the need to build the necessary health human resources and also to do so in flexible ways which maximised the limited resources available, UNAM, which is the only university in Namibia, established a distance education department - the Centre for External Studies (CES) - to support the university's first five-year development plan (1995-1999).

In other words, UNAM initiated a distance education Bachelor of Nursing Science degree to respond to the specific HR needs in Namibia. This had the potential to enable health professionals such as nurses to be upskilled through distance education while remaining in employment, thus avoiding further negative impacts on the country's health resources. Alexander, Igumbor, and Sanders (2009) found that health professionals at the School of Public Health at 
the University to the Western Cape have benefited immensely from the updating of their knowledge via a distance education course. They asserted that the success of the courses offered was, in part, due to both adequate and effective support services and also the appropriate technology.

\subsection{Problem Statement}

However, despite UNAM's efforts to contribute to Namibia's health human resources development strategy by offering distance mode, postgraduate training for nurses to prepare them for either managerial or educator positions (Bachelor of Nursing Science), the numbers of graduates remains inadequate while a high percentage of the students discontinued their studies. In addition, some students have also taken up to seven years to complete their studies.

In view of the fact that student support is considered to be an important component of student retention and student success (Sewart, 1992) and also because it is only through such student retention that UNAM will be able to contribute to the health human resources needs of the country, this study seeks to throw light both on the way in which current students experience the support services on their respective campuses and also on whether there are any significant support challenges facing students on the different campuses.

Students who reported greater perceived faculty support were more likely to persist throughout a nursing program than students who withdrew either voluntarily or because of academic failure (Shelton, 2003). A study on the integration of web-based learning communities and collaborative group assignments into the course design has revealed a positive influence on student retention in online courses (Fisher, \& Baird, 2005).

This issue of student retention is such a pressing issue in the global context of widening participation for under-represented student groups such as distance education for nurses, increasing student diversity and educational quality assurance and accountability processes. A study conducted by (Thomas, 2008) in Australian Universities revealed that there is personal impact and financial implications for students, society, families', and economy through the loss of potential skills and knowledge.

While students who do not complete may still benefit

From skills developed, including increased confidence and life experiences (Thomas, 2002) in the current competitive and globalized higher education market, the reputational fall-out of low student retention and high student attrition figures can be damaging for institutions (Thomas, 2002).

\subsection{Research Question}

The study sought to address the following research questions, namely: 1) How are existing supports needs experienced and perceived by students on the two campuses? and 2) How could the support services be made more accessible to the students and also more appropriate to their needs?

\subsection{Research Purpose}

The aim of this study was to explore the students' experiences and perceptions of the administrative, social and academic support services provided by CES in the distance mode, Bachelor of Nursing Science degree at the University of Namibia.

\subsection{Research Objectives}

The objectives of the study included the following:

- To describe the conceptualisation and resulting support services offered by UNAM on the two campuses between 2005 and 2011.

- To describe and compare the needs and challenges of distance mode, Bachelor of Nursing Science students on the two UNAM campuses.

- To describe students' perceptions and experiences of the support services offered by the CES at UNAM.

- To compare the experiences of the Bachelor of Nursing Science students of the support services offered on the two UNAM campuses.

\subsection{Significance of the Study}

It is hoped that by gaining an understanding of the students' support needs, the CES will be able to enhance future support services and arrangements, thereby contributing to improving the student graduation rate and the pace of completion of the students' studies. 


\section{Study Design and Research Methods}

The research design used was exploratory while qualitative methods were used to enable the researcher to gain an in-depth understanding of the perceptions and experiences of the Bachelor of Nursing Science students with regard to the student support services. The study enabled the researcher to identify challenges and enablers within the existing support services. The study also conducted a comparison between the student supports services offered at the two campuses. The study found varying rates of discontinued students across the years as well as different support services. A qualitative study was deemed to be appropriate as it allowed the exploration of "lived experiences in a naturalistic environment" (a distance learning campus in this instance) (Maree, 2013).

\subsection{Study Population}

The study population included any students who had been enrolled for more than two years for the Bachelor of Nursing Science degree during the period 2005 to 2011 and who had received support services from either the Northern or the Central Campuses.

\subsection{Sampling and Sampling Size}

The sample was purposively selected to represent as wide a range of experiences of the support services as possible (a maximum variation sample). In this way, the researchers sought to obtain a broad scope of information and perspectives on the research topic (Durrheim, 2007, p. 290). Accordingly, students who had "discontinued" the programme (but who had been enrolled between 2005 and 2009 at either campuses) were also included to enable the researcher to explore whether their experiences differed in any significant way from those of students who had continued with their studies.

The student sample was as follows:

\begin{tabular}{ll}
\hline $\begin{array}{l}\text { (a). Current Bachelor of Nursing } \\
\text { Science students }-20\end{array}$ & $\begin{array}{l}\text { Ten from the Northern } \\
\text { Campus } \\
\end{array}$ \\
& $\begin{array}{l}\text { Ten from the Central } \\
\text { Campus }\end{array}$ \\
\hline $\begin{array}{l}\text { (b). Students who had } \\
\text { discontinued their studies }-6\end{array}$ & $\begin{array}{l}\text { Two from the Northern } \\
\text { Campus } \\
\text { Three from the Central } \\
\text { Campus }\end{array}$ \\
&
\end{tabular}

The following seven key informants (KIs) were included:

\begin{tabular}{ll}
\hline PERSON & PLACE \\
\hline a. Director of CES -1 & One from the Central Campus \\
\hline b. CES support staff -2 & One from the Northern Campus \\
& One from the Central Campus \\
\hline c. Nursing Science lecturers -2 & Two from the Central Campus \\
& None from the Northern Campus \\
& Lecturers who taught different modules were selected \\
\hline d. Administrators -2 & One from the Northern Campus \\
& One from the Central Campus \\
\hline
\end{tabular}

\subsection{Data Collection}

The requisite data were gathered by means of focus group discussions. This method was chosen because it allows the researcher to obtain the participants' perceptions and interactions as regards an issue of common interest and in a setting that is open-minded and relaxed (Burns, 2013). It is widely believed that focus groups provide a sense of "safety in numbers" for participants who may be wary of researchers (Burns \& Grove, 2013).

\subsection{Data Analysis}

Thematic content analysis was conducted, using the research objectives as a reference framework. The researchers immersed herself in the texts, that is, the field notes and transcripts, repeatedly to try and gain an insight into the life world of the respondents (Burnhard, Gill, Treasure, \& Chadwick, 2008). The researcher's initial impressions of the 
trends in meaning which emerged were noted down in a study journal. The researcher reread the transcripts several times before starting to categorise/code the data (Burnhard et al., 2008). The process of coding involves identifying words and phrases (codes) which give meaning to certain feelings, perceptions, behaviour and/or concepts and then noting down as many codes as are necessary to describe all the aspects of the content (Burns \& Grove). The transcripts were then reread by the researcher and the codes were clustered and combined where appropriate to form sub-themes and, finally, themes under a wider category system (maree, 2013).

These themes were then compared in order to identify commonalities and differences between the two campuses. The researcher attempted to ensure that the themes related to as much as possible of the interview data that were pertinent to the research questions (Burnhard et al., 2008). Illustrative quotations from the transcripts were identified as evidence of the themes and sub-themes which had emerged and were included in the findings (Green \& Thorogood, 2009).

\subsection{Trustworthiness of the Study}

In qualitative research rigour refers to both the validity and the reliability of the study (Cresswell \& Miller, 2000). Rigour is account for at multiple stages of the research process. In order to achieve rigour, Cresswell and Miller (2000) advocate ensuring the credibility of the study. In this context, this refers to how accurately the account provided represents the participants' realities relating to the social phenomena under study.

\subsection{Ethical Considerations}

Permission to conduct the study was obtained from the Director of the Centre for External Studies at UNAM. Prior to this permission to conduct the study had been verbally negotiated with the Head of Department of this unit.

\section{Results}

\subsection{Theme 1 - Understandings of Support}

The participants discussed both their needs and their understanding as pertaining to student support. In other words they expressed their needs as learners in their respective regions. This was important to enable the researcher to understand the lived experience of the enrolled students with their evaluator views and concerns related directly to their own understandings of what student support should entail.

\subsubsection{Social and Financial Support}

The students understood support as including feelings of acceptance and assistance within the family and the workplace and from friends. They highlighted the crucial role of social support during their study years as such support enabled them to leave their homes, attend vacation schools which were often at some distance from their homes and, when necessary, to spend hours at either the library or at work with their peers, completing their assignments or preparing themselves for the examinations.

I should receive support, for example, from my family

Students from the Northern Campus appeared to understand support in terms of the way in which family members enabled or facilitated them to have more time in which to study by taking over household chores and also by providing financial assistance so that they could study. This sense of entitlement to support from the family suggests that these students perceived their choice to study as benefiting the entire family. In other words, it was not solely an individual choice or personal career decision, with the students implying that this type of support was to be expected when one studies.

The participants' perceptions of the need for social support from the family were clearly expressed as follows by students from the majority of students from the Northern Campus, including the following remark from some of the student who had terminated her studies.

"Maybe by giving you time to work on your assignments... You feel they should free you at home from your household duties."

\subsubsection{Recognition and Reward in the Workplace for Studying}

Study leave was regarded as an essential element of support by the majority of students of the Northern Campus. They indicated that it as there was always a problem if they wanted time off for study. The students noted that preparing for examinations was not always seen as a priority by their either supervisors or their colleagues at work and that this limited the time available to them for intensive study. In practice, students receive two study days prior to examinations from the Ministry of Health and Social Services. Below are some statements from some of the participants: 
"I think they must provide us with more study leave because we are struggling with it. We have been given two days before the exam which is not really enough."

\subsubsection{The Need for Academic Guidance}

The students from the Northern Campus expressed a need for guidance from the lecturers. It is possible that this need may be greater on the Northern Campus than the other campus because of the greater separation between students and lecturers on the Northern Campus. These students also expressed the need for more guidance via tutorial letters and assignments. Majority of students expressed their need for lecturer support in the following ways:

"If lecturers can guide you more on what we are supposed to do, it will be better."

\subsubsection{What is Needed from the Institution}

The students from both the Central Campus and the Northern Campus expressed the need for resources to be available as well as for the timely despatch of study material. Study materials are usually prepared in October of the previous academic year and should be ready for despatch by the beginning of February of the following year. The students noted that, throughout their years of study, they had experienced difficulties in relation to receiving their study material on time and that this, in term, affected them in terms of submitting their assignments by the due dates. Below is one of the statements from some of the participants:

"Uhm [clears throat] my suggestion is just that, at least uh, uhm, [we should have our materials at the] beginning of the academic year when we have to register."

The timely despatch of study materials to students is essential in a distance education institution. Students need time in which to consolidate the content in order to prepare for their assignments and, thus, when it arrives late, this has an impact on both their ability to submit their assignments on time and on the lecturers' ability to provide them with timely feedback. The importance of the timely despatch study materials to students was acknowledged by a staff member who commented. Below is statement from of some of the participant:

"There are many things which need to be in place - it does have an effect on efficiency as [the university] is offering a dual teaching mode, i.e. we offer the same packages also to full-time students, therefore we need to communicate timeously."

\subsubsection{The Need for Good Communication}

The need for good, accurate and timeous communication with students was deemed to constitute essential support service by the participants. It was also noted by one of the senior staff members at the CES that good communication and the sound preparation of students are essential when students are required to attend workshops and vacation schools if these events are to be of any value to the students. Below is one of the statements from some of the majority of the participants:

"Tutorial letters or activities should be sent out to students timely so that they can prepare themselves and come prepared when the video conference or the vacation school starts."

\subsubsection{The Need for Mentorship}

The mentoring of students is one of the strategies used in distance education in order to guide and counsel students and to assist them in overcoming challenges they may encounter during the course of their studies. The key informants viewed mentoring system as an extremely important tool in assisting the students in rural areas to progress in their studies. One of the key informants remarked:

"You can start a mentoring system for students in the far remote areas. But this takes money. You can get someone to assist students far in the North with social support but people want to be paid"!

\subsubsection{The Need for a Follow-up System for Students}

It emerged that monitoring or follow up in terms of which the academic progress made by students is reviewed in order to prevent students terminating their studies were not conducted regularly and in a formal way by the lecturers, although end of year discussions were held in order to make decisions regarding the progress of students or the termination of their studies. A student may be required to terminate his/her studies should the student not have passed at least five modules in the first year, nine in second year, 13 in third year, or 22 in the sixth of year of study or when the maximum period of six years allowed has been exceeded. 
The need for timely follow-up was expressed by one of the educators at the Central Campus as it would seem that lecturers often lose track of students if they do not hand in their assignments or if they "terminate their studies" halfway through the year. Below are some expressions from some of the key informants:

"Follow-up is definitely lacking. Some students just fade away, you don't keep track. I don't keep a good system because you only realise it when it is November and it is exam time."

3.1.8 A Need for the Rotation of Support Programmes at the Regional Centres

It emerged that the students from the Northern Campus have to spend time travelling to the Central Campus in order to attend the skills workshop and sometimes the vacation school in mid-July. This entails considerable travelling costs as well as time off from work. A few of the students expressed the need for the lecturers to present the skills workshop on the Northern Campus and even suggested that this could be done on a rotational basis:

"Why can't they send lecturers to [...] to do the skills workshop? Maybe this week in Keetmanshoop, next week in Oshakati, then next time in Windhoek."

\subsubsection{Equipping Educators for Distance Education}

One of the senior staff members at the CES indicated that the vision for the CES is the on-going development of educators for the purposes of distance education. She mentioned that educators have been sent to some of the most developed countries to attend conferences and courses to equip them to develop online course materials. Below is one of the expressions from one of the key informants:

"We are thinking of developing course material that can be available on line as at the University of Nottingham in the UK."

\subsection{Theme 2 - Being a Mature, Working, Part-time Distance Student}

This theme encapsulated some of the positive experiences and challenges experienced by registered nurses studying for the Bachelor of Nursing Science Degree. The views they expressed views on their experiences also served as an evaluation of the support they had received. The positive experiences of support - personal and institutional - are discussed under Themes 4 and 5. Some of their experiences differed in intensity as a result of their sense of separation as a result of both distance and other factors which are described in detail.

\subsubsection{Personal Experiences: Social Implications of Part Time Distance Education on Student and Juggling of Roles}

Many of the participants mentioned that their simultaneous roles of full time nurse, mother to small children and housewife at the same time had interfered with their studies. One of the participants revealed:

"Because, I have small kids, when you want to go to the library or go out, they don't want you to go out."

\subsubsection{Ill-health and Subject Overload}

The Centre for External studies has its own specific rules for the progress of students with ill-health and pregnancy being accommodated on condition that the student does not exceed the extended time allowed to complete the programme. Students often enrol for additional subjects in order to complete their study programme in a shorter time and they sometimes over-estimate their own capacity. In addition, when social issues arise, e.g. marriage, then the demands of the programme may become too much. In fact, marriage was the reason why two students had terminated their studies, one at the Central Campus and one at the Northern Campus.

Pregnancy and ill-health were the reason why one of the students at the Central Campus had terminated her studies as they had impacted on her progress to the next year/level. She stated:

"In 2011, when I came to register, I put in more effort, but I became pregnant. By March 2011, I became sick."

\subsection{Theme 3 - Institutional Weaknesses in Programme Delivery}

\subsubsection{Late Materials}

The late delivery of materials was a recurring theme which dominated the interview sessions throughout. Despite the researcher trying to steer the discussion in the direction of the participants sharing their experiences on the quality of the supplementary support strategies, they clearly urgently needed to talk about the weaknesses they had encountered in the delivery of the programme itself. One of the participant commented:

"I just want to comment on the materials. They come late, very, very late". 


\subsubsection{There's always Someone Waiting for the Book}

The challenge of accessing study material was compounded by the difficulties involved in accessing the prescribed books at the libraries. This issue was raised by majority of the students from both campuses. One of the participants observed:

"We also find it difficult to get the prescribed books. Most of the prescribed books are reserved-you can only keep it for 12 hours.

The reluctance on the part of the students to buy books was often the result of financial constraints as discussed previously. Some of the participants also expressed the opinion that the CES should provide most of the reading materials this attitude of entitlement among the students was confirmed by one of the educators:

"There are factors which hinder/influence adequacy. Money, distances, literacy of students".

In addition, out-dated library resources at the university were cited as one of the main factors that had resulted in one of the students terminating her studies. One of the participant commented:

"First time I started in 2001. I was based in a rural area and the resource which we used a specific library".

\subsubsection{Inadequate Resources for Examination Preparation}

The students referred to the resources in the library as inadequate as they could often not access old examination papers. It appeared that the majority of students depended on old examination papers as they used these to study and prepare themselves for the examinations. A student at the Central Campus was of the opinion that the past examination paper resources at the library were also "out-dated" and not always accessible. This had left her with feelings of "despondency" and "uncertainty" with regards to the structure of the examination papers. One of the participants mentioned:

"You don't have access to past question papers. The library apparently has a site, you go to the library and sit there the whole night and you can't access that site".

\subsection{Theme 4 - Experiences of institutional Support}

Although the participants did not distinguish between programme delivery strategies and support mechanisms such as video-conferencing, this section will focus primarily on their views of the support mechanisms provided, namely, the support from educators, access to the Internet, and the support received from the video conferences (vacation schools) and skills workshop.

\subsubsection{Experiences Pertaining to Lecturer Support}

The participants maintained that lecturer support was available when they contacted the lecturers who would assist them when they encountered any problems. Some maintained that the improvement in their writing skills was the result of the lecturers guiding and assisting them in this way. Although the educators had cited academic writing as an issue of concern some of the students had cited the improvement in their academic writing as a positive acquisition. One of the students from the Central Campus expressed herself as follows.

"What I experienced a lot is that I learnt how to do, how to write in academic format."

\subsubsection{Access to the Internet}

The university offers free access to the Internet to all students on both the Central and the Northern Campuses. It appeared that several of the participants made effective use of this service.

"I used all the options and even the Internet provided on campus as well as my cell phone."

"Yes, I made use of Internet and found it quite useful. I made use of the Internet at [the university] campus."

\subsubsection{Experiences of Video Conferencing}

The video conference has already been described as a key support strategy. As has been discussed, video conferencing was started in 2005 at the CES as a way of providing student support and in order to supplement the text based material. The video conferencing is transmitted from both campuses. However, the study found that the transmitting of the video conferences presented numerous technical challenges, e.g. poor imaging which hampered the concentration of the students as well as interruptions due to technical problems, especially for the students on the Northern Campus, and resulting in the lectures not always being "fully understood" or "heard" at times. One of the participants had this to say on the quality of the video conferencing:

"Most of the lecturers come in front of camera but, otherwise, you can't always see them." 
The majority of participants from the Northern Campus also complained that there was often no technical person available when technical difficulties arose, thus leaving them to scour the campus for someone to help with this resulting in their missing the greater part of the lecture. Although provision had been made at each campus for a technical person to be on standby, it appeared that was not well organised on the Northern Campus. The participants commented as follows:

"They let the students in at the venue but there is nobody to operate the video."

"You need to go back to [call] someone to come and manage but then you miss part of the lecture."

On the other hand, the video conferences were also acknowledged to be useful by the students, mainly from the Northern Campus. This was corroborated by one of the students who had terminated her studies.

This was also affirmed by one of the staff members at the CES. She stated:

"Let me be honest with you and say that you may have the best of technology at hand but, if little preparation or none is made prior to the video conferencing, then the best type of technology is not worthwhile".

\subsubsection{Experiences of the Skills Workshops}

The skills workshop is offered once a year, usually in the first week of October. The aim of this workshop is to focus on the practical aspects of the students' selected specialisations as well as on teaching students the skills required to interpret and answer examination questions. One of the participants had the following to say regarding her experiences at the skills workshops:

"both of these (skills workshop/video conference) are very important. I learnt a lot from them, especially from the skills workshop."

It appeared that the she Skills workshop was appreciated by students from both the Central and the Northern Campuses as they were able to experience the lecturer and peer interaction which they were missing while they were also able to share some of their academic problems with the lecturer and the rest of the class. The participants made the following statements regarding the skills workshop:

"Ok, to me, the support is this vacation school [skills workshop]. It really helps us. You can go through the content and the assignment and you can ask questions".

\subsection{Theme 5 - Experiences of Social Support}

The study found that social support was particularly valued by the students from the Northern Campus. It seemed that the students perceived support in terms of the way in which family members enabled or facilitated them to have more time to study by taking over household and other social responsibilities.

\subsection{1 [My] Greatest Support was My Family}

Majority of students described their families as one of their greatest support structures - either their husbands or their children. The participants stated:

"I think my greatest support was my family. When I sit with my assignments, I don't have colleagues".

\subsubsection{Support from Employers}

In spite of the difficulties and red tape related to the students' need for support from their employers, some of them were extremely appreciative of the support they had received. Some of them noted that their employers had provided them with information required for their studies and had accommodated them when they had needed to change their shifts. Employers or supervisors were also reported as extremely accommodating especially by the students on the Central and Northern Campuses and who had terminated their studies. One of the participants had this to say on the support she had received from her supervisor:

"I spoke to my supervisor and she said if you don't want night [duty] you just put in a request that you don't want night duty. But that was after everything went wrong."

\subsection{Theme 6 - Inherent Motivation}

\subsubsection{Inherent Motivation}

Students from both the Central and Northern Campuses referred to their own "personal motivation" as a factor which had enabled them to pursue or persevere in their studies. This type of inherent motivation had them to overcome the challenges they had encountered and to strive towards their end goals. The students expressed the view that the fact that they had acquired knowledge during their years of study, that they had been able to progress in spite of the 
challenges encountered and that they had been able to upgrade their qualifications had inspired them to continue studying. One of the participants mentioned that she had learnt to balance her household chores with her studies, thus implying that she had learnt the techniques of effective time-management and self-directed study. Other mentioned that they had been able to put into practice what they had learnt as working students. Two of the students (who had discontinued their studies) indicated they wanted to continue studying in the field of medicine.

The participants shared the following:

"Uhm, for me, I have experienced a lot because through studying you acquire a lot of knowledge and that is what inspires you to go ahead and put into practice what you've learnt."

One of the key informants (an educator) expressed that she hoped that the students had experienced personal growth and empowerment during their years of study.

"A study was not done. It's complicated. You have to see beforelafter. Hopefully it broadened their world view - [it was] supposed to improve their skills".

Inherent motivation had also succeeded in making students want to continue their studies (as expressed by two students who had discontinued their studies (Northern Campus).

"I already have my diploma but I need to upgrade although I do not get more money. I grow in the profession and become empowered, which will help the nursing profession."

Not all the students who had discontinued their studies had done so because of academic or social difficulties, poor results or a lack of support. Instead, one student noted her dissatisfaction that the degree itself would not make any material difference to her conditions of work and salary. Nevertheless, as she was extremely ambitious, she had decided to study medicine through the University of China.

"No I want to study medicine so I want to save some money as I want to study at the University of China".

\section{Discussions}

The findings of this study reflected the experiences of students relating to the support they had received during the course of their studies during the period 2005 to 2011, as well as their understandings of support. One of the students who had terminated her studies indicated that her household responsibilities and child minding, i.e. the juggling of roles, had become too challenging and she had been unable to cope with the demands of her studies.

Both students and educators highlighted the essential need for both academic guidance and academic support. Many of the student participants expressed the need for lecturers to provide them with more support in the form of feedback on assignments or more tutorial letters (Mowes, 2005).

Mentorship for students was identified as a useful support mechanism or strategy, especially for students in the rural areas where the feeling of isolation from the main campus is intensified. Mentorship has been accepted by many distance education centres as a vital support strategy with which to sustain students during their course of study.

A dominant theme which recurred was the need for the timeous despatch of study material. This was expressed by all the students from both the campuses. This theme was not intended to be a point of discussion nor was it referred to during the interviews. However, it arose spontaneously out of focus groups when the participants referred to their negative experiences of support. This "basic necessity" appears to be a common problem at distance learning centres (Mowes, 2005; Mbukusa, 2009; Ngoma, 2004). Findings from a study conducted at the University of Ghana revealed that $81.5 \%$ of students in the distance education programme complained of study material not being available (Siabi-Mensha et al, 2009). Mbukusa (2009) highlights in the findings of his study conducted at the University of Namibia that the general complaints of students at the Northern Campus pertained to the unavailability of study material which had a negative impact on the students.

The factors discussed all contributed to the high attrition rates, with many of the students having to terminate their studies as they had exceeded the required years of study (Ngoma, 2004; Siabi-Mensha \& Torto, 2009; Thompson, 1997). Thompson (1997) also concluded in her study conducted at the Edith Cowan University that one of the reasons for the student drop out was the "juggling of roles" experienced by her participants (external students enrolled in the fourth year of the Bachelor of Education course).

The students also complained that communication was often poor with regard to the dates of workshops, vacation schools and video conferences (Thompson, 1997). Mowes (2005) identified improved communication as essential if the University of Namibia wishes to be efficient and true to its goal of striving for excellence in the delivery of its distance programmes. 


\section{Conclusions}

A range of support services are conceptualised and implemented, e.g. library services, Internet access, tutor-marking, telephone tutoring, video conferences, and skills workshops, and presented via the vacation schools. However, it appeared many of these support services were not accessible to students on the Northern Campus, for example Internet access or library resources as a result of the distances between their homes and the regional offices and/or the Northern Campus.

\section{Recommendations}

The following recommendations are made based on the findings of the study:

- The CES should investigate better supervision and coordination regarding the preparation and delivery of study material.

- The CES should seek to improve communication with the campus bookshops to ensure the availability of the prescribed books.

- The University library should be purchasing more e-books contracts with publishers, making this available to all students over the internet.

- A schedule of assignment deadlines, workshops, video conferences and examinations should be drawn up and issued before the programme starts and not changed if at all possible.

- The CES and its educators should devise an improved method and schedule for supportive consultation with students. In addition, they should inform students of the times they are availability together with their necessary contact numbers well in advance of the commencement of the programme.

- The video conferencing on the Northern Campus should be supervised effectively by the administrative management of the Northern Campus to ensure that a technical person is available during video conferencing.

- To promote retention, instruction should be given to employers and family as a way of providing guidance for employers on how best to support studying employees and so for families.

- Administrative and lecturing staff should undergo refresher training on distance education from time to time to ensure that are aware of the challenges facing their students who both work and study and also have to travel long distances in order to collect materials, etc.

\section{Acknowledgements}

We wish to thank all the respondents who took part in this study. Without their participation this study would not have been even a success or even possible. We also wish to thank the University of Namibia (UNAM) for granting us permission to conduct this research study on its premises.

\section{Competing interests}

The researchers declare that they had no financial or personal relationship(s) which may have inappropriately influenced them in the writing of this article.

\section{References}

Alexander, L., Igumbor, E. U., \& Sanders, D. (2009). Building capacity without disrupting health services: Public health education for Africa through distance learning. Human Resource for Health, 7(1), 1. http://dx.doi/org/10.1186/1478-4491-7-28

Burnhard, P. (1991). A method of analysing interview transcripts in qualitative research. Nursing Education Today, vol. 11(6), 461-466. http://dx.doi/org/10.1016/0260-6917(91)90009-Y

Burnhard, P., Gill, P., Treasure, E., \& Chadwick, B. (2008). Analysing and presenting qualitative data. British Dental Journal, 204(8), 429-432. http://dx.doi/org/10.1038/sj.bdj.2008.292

Burns, N., \& Grove, S. (2013). Practice nursing research. Philadelphia: W.B. Saunders.

Cresswell, J. W., \& Miller, D. L. (2000). Determining validity in qualitative inquiry. Theory into Practice, 39(3), 124-129. http://dx.doi.org/10.1207/s15430421tip3903_2

Department of Education. (2007). A draft policy for open, distance and e-learning (ODL) for Namibia. Windhoek, Namibia. 
Fisher, M., \& Baird, D. E. (2005). Online learning design that fosters student support, self-regulation, and retention. Campus-Wide Information Systems, 22(2), 88-107. http://dx.doi.org/10.1108/10650740510587100

Global Distance Education. (1999). Policy \& programs: Centre for External Studies. University of Namibia: SAIDE.

Green, J., \& Thorogood, N. (2009). Qualitative methods for health research methods. Los Angeles, CA: Sage Publications.

Maree, K. (2013). First steps in research. Pretoria: Van Schaik.

Mbukusa, N. R. (2009). Barriers to remote rural students' access of distance education support services offered by the Centre for External Studies at the University of Namibia. (Unpublished doctoral thesis). Pretoria: University of South Africa.

Ministry of Health and Social Services (MOHSS). (2008). The Health and Social Review. Windhoek: MOHSS.

Mowes, D. L. (2005). An evaluation of student support services in open and distance learning at the University of Namibia. (Unpublished doctoral thesis). Stellenbosch, South Africa: University of Stellenbosch.

Ngoma, P. (2004). Assessment of distance learning programs and factors that contribute to the dropout rate among distance students at the University of Zambia. Retrieved March 13, 2012 from http://pcf4.dec.uwi.edu/viewpaper.phpid

Sewart, D. (1992). $16^{\text {th }}$ World Conference of the International Council for Distance Education. Student Support Systems in Distance Education. Paper. November 8-13. Bangkok, Thailand.

Shelton, E. N. (2003). Faculty support and student retention. Journal of Nursing Education, 42(2), 68-76. www.ncbi.nlm.nih.gov/pubmed/12622334

Siabi-Mensah, K., Badu-Nyarko, S. K., \& Torto, B. A. (2009). Problems of part-time students in Ghana: Implications for distance education. Turkish Online Journal of Distance Education, 10(4), 175-187. http://www.ug.edu.gh/aehrs/staff/drsamuel-kofi-badu-nyarko.

Tait, A. (2000). Planning student support for open and distance learning. Open Learning, 15(3), $287-299$. http://dx.doi.org/10.1080/713688410

Terre Blanche, M., \& Durrheim K. (Eds). (2007). Research in practice: Applied methods for the social sciences. Cape Town: UCT Press.

Thomas, L. (2002). Student retention in higher education: the role of institutional habitus. Journal of Education Policy, 17(4), 423-442. http://dx.doi.org/10.1080/02680930210140257 